Research Article

\title{
Diversity and Trophic Relationships of Functional Groups of Bumblebees (Hymenoptera: Apidae, Bombus Latreille, 1802) in Urban Habitats
}

\author{
Hanna Yu Honchar \\ Institute for Evolutionary Ecology of the National Academy of Sciences of Ukraine, Lebedeva Str. 37, 03143 Kyiv, Ukraine \\ Correspondence should be addressed to Hanna Yu Honchar; apantova@ukr.net
}

Received 11 February 2020; Revised 20 August 2020; Accepted 11 November 2020; Published 7 December 2020

Academic Editor: Jacques Hubert Charles Delabie

Copyright ( $\odot 2020$ Hanna Yu Honchar. This is an open access article distributed under the Creative Commons Attribution License, which permits unrestricted use, distribution, and reproduction in any medium, provided the original work is properly cited.

\begin{abstract}
Species composition, distribution, and trophic relationships of bumblebees are studied in six types of urban habitat: urban parks, botanical gardens, least-disturbed areas within the city, residential areas, and roadsides. Twenty bumblebee species are recorded in the present study. The species composition of bumblebees has changed from 1933 to 2017. Rare species have disappeared from the city-Bombus fragrans, B. cullumanus, and B. jonellus. The core of urban bumblebee communities consists of ecologically plastic species, most of which belong to the functional morphoecological "short-tongued" group (83\%). The more specialized "mediumtongued" and "long-tongued" species are less diverse. Their populations make up $14 \%$ and $3 \%$ of the total bumblebee population. Five most common species, B. lucorum, B. terrestris, B. lapidarius, B. pascuorum, and B. hypnorum, are found at locations of the most noted categories of habitats. One of the main factors affecting the diversity of morphoecological groups of bumblebees in urban conditions is the state of floral resources. The bumblebees are observed feeding on more than 60 plant species of the families Asteraceae, Fabaceae, Lamiaceae, Rosaceae, and Salicaceae in urban environment; however, the insects favored plants of 30 species. The ornamental, ruderal, and some invasive species of plants are significant in bumblebees' feeding in urban conditions. The resources for bumblebee feeding and sustainable density of nesting sites are rich in quality and quantity only at a few of model urban sites. At these territories, the highest species diversity of bumblebee is recorded, including rare, protected, and vulnerable species. The ecological potential of other studied urban sites is enough to sustain the most ecologically plastic bumblebee species.
\end{abstract}

\section{Introduction}

There are almost 250 species of bumblebees worldwide, 42 of which are found in Ukraine [1,2]. These insects are very ecologically and economically important as the main pollinators of wild angiosperms and many food crops $[3,4]$. Populations of many bumblebee species have drastically declined worldwide, particularly at Western Europe [5-11]. Thus, $24 \%$ of the European species of bumblebees are protected by the European Red List of Bees, and the density of $46 \%$ of species declines [12].

The main reasons of the falling diversity of bumblebees are thought to be the habitat losses and the decreasing density and diversity of plants [4-7, 10, 13-18]. Urban green areas, such as parks, botanical gardens, remnants of natural landscapes, green backyards, etc., can sustain various bumblebee species because there are different plant associations providing successions of nesting habitats and flowering plants $[9,17,19-22]$. However, the increasing human impact forces the decrease of bumblebee species diversity $[11,16,21,23,24]$.

In the course of evolution, bees adapted to collecting, feeding, and transporting flower nectar and pollen using various functional morphological structures [24-27]. The proboscis, comprised of the maxillae and labium, serves to extract nectar from flowers [28] and affects flower choice [29]. Therefore, this morphological structure, in particular the length of the tongue (= glossa), determines the depth and the rate from which a bumblebee can obtain nectar [29]. Correlations between the depth of flowers visited by bees and their tongue lengths have been reported frequently [26, 28-32]. Consequently, this morphological character can 
predict the plant species that will be visited by a particular bee. For example, "long-tongued" bumblebees are specialized to flowers with elongated corollae [32]. "Short-tongued" bumblebees usually feed on flowers with shallow corollae; also they can gnaw through walls of flowers with deep corollae [32-34]. The bumblebees with short and medium length of tongues change environment by using various feeding resources $[5,24,35,36]$. Based on this information, some studies have shown that diversity of bumblebee communities (including indicated parameter " tongue length") is increasing with plant species enrichment $[6,14,31,37]$.

In Ukraine, the bumblebee diversity was researched in some cities: Lviv, Lutsk, Ternopil, Uzhhorod, and Chernivtsi [38]. However, it was not studied in one of the largest cities of Ukraine, Kyiv. Nevertheless, Lebedev [39] in year 1933 conducted a survey of bumblebee diversity and specifics of ecology at the territory of Kyiv and surroundings. In that publication, the composition of wild bees in general and of their host plants is given with the sampling locations in Kyiv region. Findings of a number of bumblebee species were also reported by Muzychenko [40, 41] and Nevkryta [42, 43].

The aim of the present work was to study the species composition of bumblebees in Kyiv, their density at different types of model urban habitats, their trophic relationships, and specifics of community structure by the morphoecological character "length of tongue."

\section{Material and Methods}

2.1. Study Area. The city of Kyiv (the capital of Ukraine, its geographical coordinates are $50^{\circ} 27^{\prime} \mathrm{N}, 30^{\circ} 31^{\prime} \mathrm{E}$ ) is located in the north of Ukraine, on the border of Polissya and the forest-steppe zone. The area of Kyiv within the administrative boundaries reaches $836 \mathrm{~km}^{2}$. The city's built-up land is $364.0 \mathrm{~km}^{2}$, and $115.0 \mathrm{~km}^{2}$ of which are under residential and public buildings. A significant amount of land is occupied by industrial facilities- $56.0 \mathrm{~km}^{2}$, objects of transport and communication $-22.0 \mathrm{~km}^{2}$. Most of the city lies on the high right bank of the Dnipro-the Kyiv plateau cut by a thick net of ravines. The smallest part is on the lower left bank of the Dnipro [44].

Study was conducted at 21 sampling locations divided into several categories (urban parks, botanical gardens, residential areas, remnants of natural landscapes, islands of the Dnipro River, and roadsides) in various districts of Kyiv from 2012 to 2017 (Figure 1, Table 1).

Some of the study locations were chosen in protected areas (such as M. M. Gryshko National Botanical Garden, Theofania, and Lysa Hora).

The sites were visited during the hours of high bumblebee activity and only under good weather conditions. Surveys of bumblebees were done from March to August; each allotment site was visited not less than 6 times per season in varying order. In 2012, Theofania park, Peremoha park roadsides, and Svyatoshins 'kii forest park were visited; in 2013-Theofania park, Babi Yar park, M. M. Gryshko National Botanical Garden, Lysa Hora regional landscape park, Dnipro River islands, and roadsides; in 2014-KPI park, Babi Yar park, Sovki, M. M. Gryshko National Botanical Garden (GNBG), and Dnipro River islands; in 2015-Theofania park, Nyvky park, Svyatoshins 'kii forest park, Vinogradar residential area, Teremki-1 residential area, Lysa Hora regional landscape park, Peremoha park, and Partizans 'koi Slavy park; in 2016-Theofania park, Nyvky park, KPI park, Teremki-1 residential area, Peremoha park, Partizans 'koi Slavy park, and Dnipro River islands; in 2017-M. M. Gryshko National Botanical Garden, Lysa Hora regional landscape park, Teremki-1 residential area, and Vinogradar residential area. The data obtained from roadsides (five points: 17-21, Figure 1) are grouped into the "Roadsides" (Figure 2).

2.2. Functional Groups of Bumblebees. The functional (length of tongue) specifics were taken from [30,31, 33, 34, 45-49]. The bumblebee species were collated by the length of tongue (Table 2) into three functional morphoecological groups with short $(6-8 \mathrm{~mm})$, medium $(8-9 \mathrm{~mm})$, and long tongues $(9 \mathrm{~mm})$. Kleptoparasites species belong to the group of "short-tongue" species.

2.3. Sample Collection. Collection of samples and observations were conducted according to Pesenko [50]: at each site, $100 \mathrm{~m}^{2}$ of transect was chosen to analyze the composition of angiosperms and bumblebee species. Bees were collected by net, while visiting flowers. The visited plants and their botanical family membership were recorded.

Individual specimens of workers and males' castes, that are impossible to identify in the field, were caught, euthanized with ethyl acetate, and brought to the laboratory for species determination. Bumblebees were determined to species following by Løken, Edwards, and Jenner $[45,47,48,51]$. The female, male, and worker specimens of rare species, including those protected by the Red Data Book of Ukraine [52] were caught, identified immediately after that, and released (B. argillaceus, B. muscorum, B. sylvestris, and several workers of B. pascuorum and B. hypnorum).

As in other studies, Bombus terrestris L. workers have been included in the B. lucorum worker totals since the two species are not readily distinguishable in the field and have close ecological preferences $[5,22,26,51,53-55]$.

2.4. Statistical Analysis. The relative density of bumblebees was calculated as the percentage of specimens of certain species to all specimens in sample.

Rarefaction curves for each collection site show the diversity detected compared with the predicted diversity for this site. The $x$-axis represents the number of sequences sampled while the $y$-axis represents the measures of the species richness detected. Hierarchical K-Means Clustering was used to process data on the composition of bumblebee communities and host plants of different territories. The linear regression was used to investigate the influence of the number of flowering plant species on species richness of bumblebees (species and individuals). This analysis was 


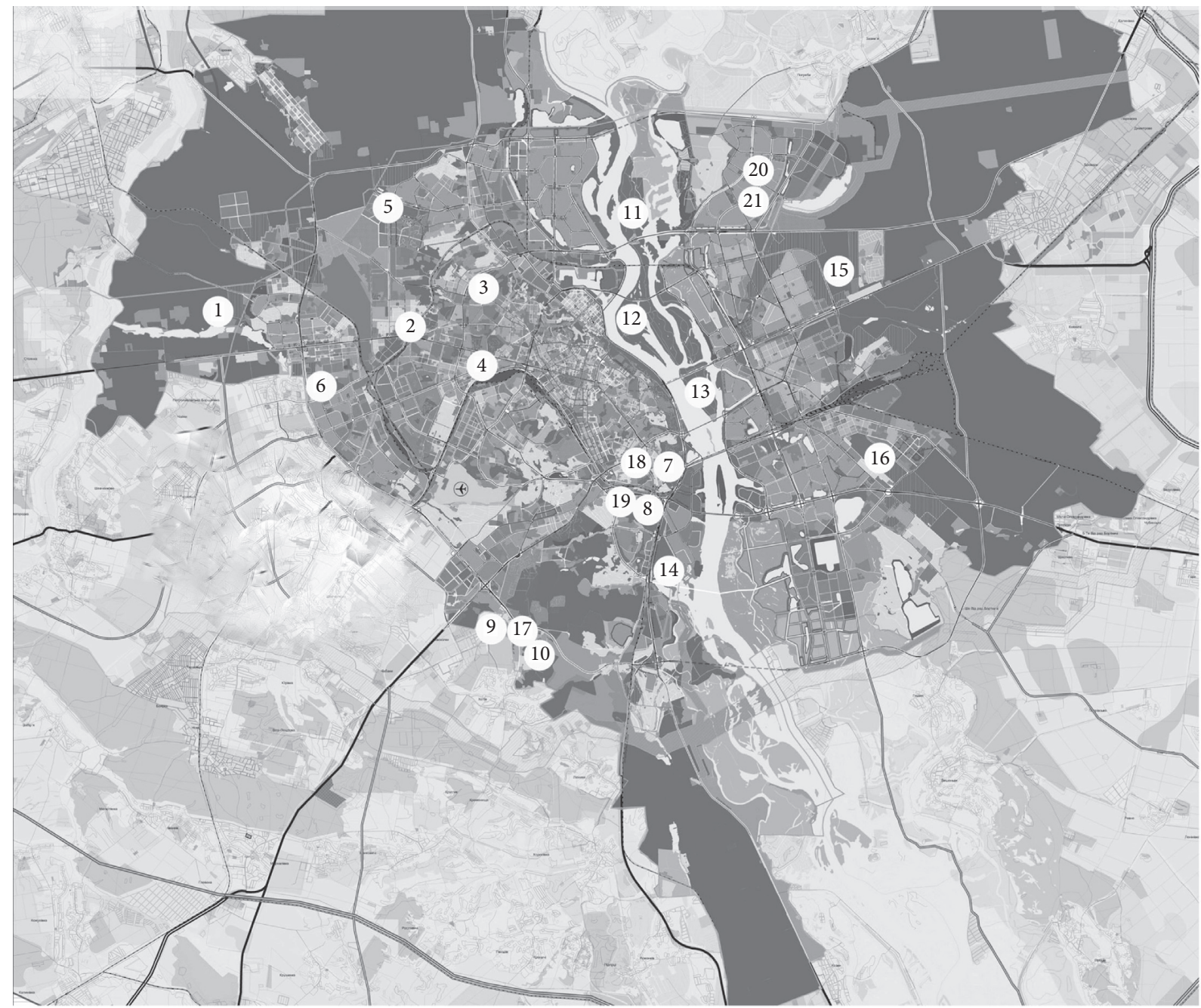

FIGURE 1: Locations of bumblebee sampling in Kyiv. 1-Svyatoshins 'kii forest park; 2-Babi Yar park; 3-Nyvky park; 4-KPI park; 5-Vinogradar residential area; 6-Sovki; 7-M. M. Gryshko National Botanical Garden; 8-Lysa Hora regional landscape park; 9-Teremki-1 residential area; 10-Theofania park; 11-Muromets island; 12-Trukhaniv island; 13-Hydropark island; 14-Zhukiv island; 15-Peremoha park; 16-Partizans'koi Slavy park; 17-Akademika Zabolotnoho Str.; 18-Druzhby Narodiv Boulevard; 19-Saperno-Slobidska Str.; 20-Zakrevskogo Str.; 21-Mayakovskoho Avenue.

performed in $\mathrm{R}$ 3.6.1 (The R Foundation for Statistical Computing).

The diversity of bumblebee samples was assessed using Shannon's index $(\mathrm{H})$ evenness index (J') [56]. The one-way ANOVA (Levene's test, Kruskal-Wallis test for equal medians) was used for comparison of the species richness of bumblebee between habitat types. These measures were performed with the computing software PAST 4.01 [46].

The trophic relations were visualized in $\mathrm{R}$ version 3.6.1 (The R Foundation for Statistical Computing) using "bipartite" package [18]. Trophic relations between bees and the respective plants are presented graphically: width of relation on one side indicates the number of visits and diversity of visitors for plants and on the other side for bees [57].

\section{Results and Discussion}

3.1. Species Composition and Species of Core Bumblebee Groups. In total, 2141 bumblebee individuals of 20 species are recorded in Kyiv (see Table 2).

According to the published data, there are 30 species of bumblebees in Kyiv region [1, 39], and 23 species have been recorded in Kyiv in 1900-1933. A. G. Lebedev has found 73\% of specimens of 13 species in Holosiyevo district of Kyiv (he has studied that part of Kyiv most extensively); he has also sampled bumblebees in KPI park, Batyieva Hora park and Kyiv (unspecified) [39]. He has considered the following species to be single and rare: $B$. fragrans (Pallas, 1771), $B$. cullumanus (Kirby, 1802), and B. jonellus (Kirby, 1802). 
TABle 1: Description of habitats.

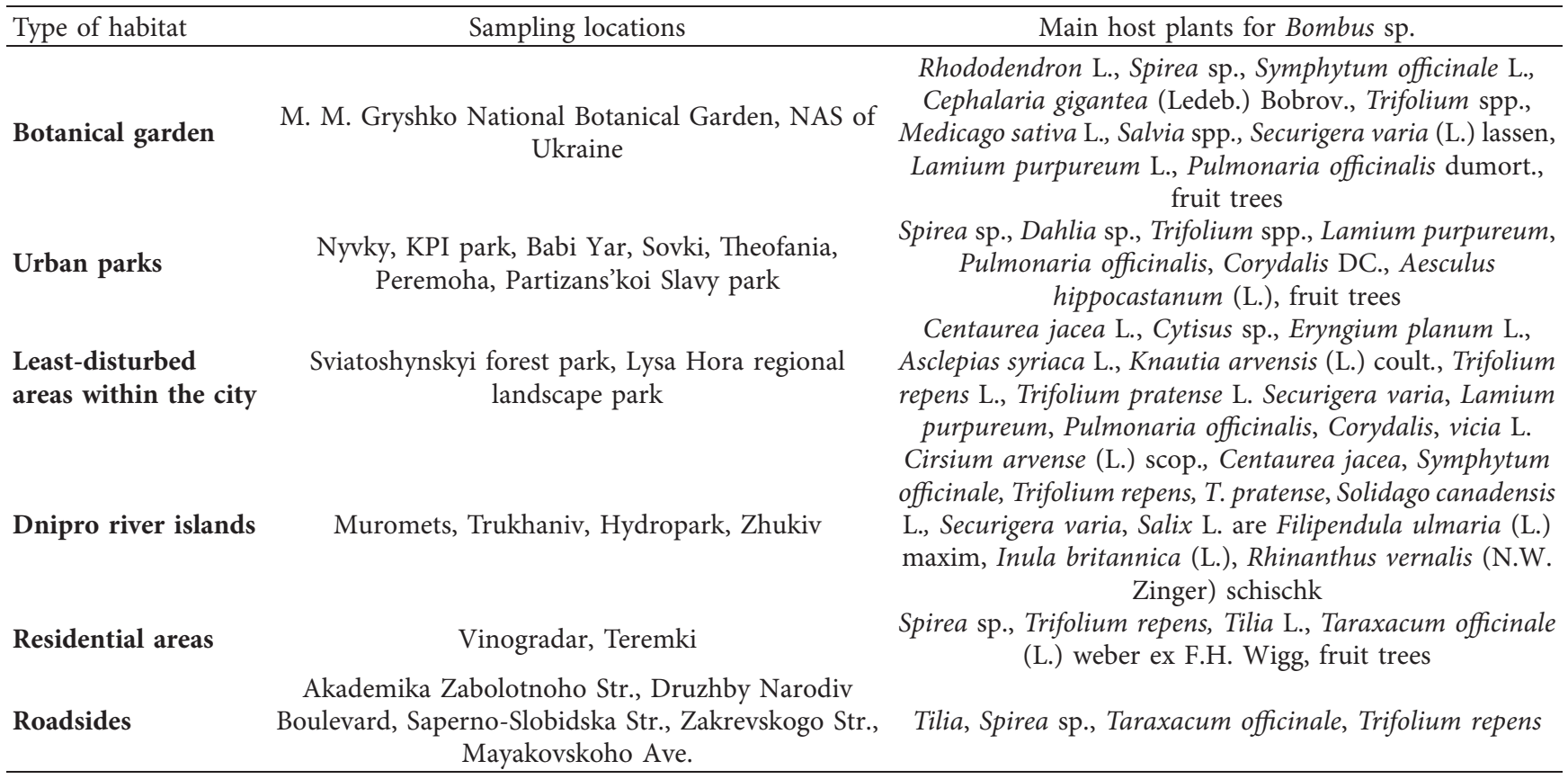

Those species are now also considered rare; $B$. fragrans is in the Red Data Book of Ukraine [52], and B. cullumanus is one of the most threatened bumblebees in Europe [58]. We did not find these species in our survey that, possibly, confirms the tendency of these species to decrease.

According to our data, five bumblebee species were relatively common in the urban environment: $B$. terrestris, $B$. lucorum, B. lapidarius, B. pascuorum, and B. hypnorum. Single specimens of B. argillaceus, B. humilis, B. muscorum, $B$. pratorum, and $B$. veteranus were found only in several urban habitats. Cuckoo bumblebees ( $B$. bohemicus, $B$. campestris, B. rupestris, and B. sylvestris) were rare and only present in the most diverse bumblebee communities. The low diversity of kleptoparasite species can be explained by the disturbances within habitats since parasitic taxa of bumblebees are very sensitive to environmental changes [59].

General diversity (species and number of individuals) differed significantly among the six habitat types (Table 3, $F=3.127, p=0.011$ ).

The analysis of rarefaction curves obtained for the sequence data (Figure 3) indicated that most of the species was detected, but these curves showed differences among habitat types in the overall number of bumblebee species recorded.

Habitat type had a large impact on the proportional abundance of the different bee groups [59]. The number of species for the botanical garden is 14, and this type of habitat, as well as some "LDA" and Dnipro islands sites, differs a large number of species. Some studies reported that a high diversity of wild bees was observed in botanical gardens [60-63]. In addition, extrapolated curves revealed that the highest diversity could be found. For habitat type "Dnipro islands," the average number of species is nine and with an increase in the number of individuals expected more twenty.
Although such a number of species is possible for Dnipro islands in total, on each island individually there are a maximum of twelve species (Zhukiv and Muromets) and a minimum of five for Hydropark island. The differences between results from different islands can be explained by site-specific characteristics (landscape structure, diversity, and abundance of plant species), which has also been shown in some studies $[15,19,59,62,64]$.

Least-disturbed areas within the city have different conditions. Lysa Hora is a locality with large areas of broadleaved forest and open meadow sites, and Sviatoshynskyi forest park is pine forest with small open edges. In this type of habitat, the maximum number of species was recorded for Lysa Hora (14 species), but as in the case of the Dnipro islands, the expected number of species can be maximum-twenty species in general. Also least-disturbed areas compared to urban parks or roadsides, most often had a high diversity of bees $[19,65,66]$. Nevertheless, some studies have reported a low diversity of bumblebees in more conserved environments compared to urban parks or human-modified habitats and this difference could be due to the concentration of resources $[67,68]$. In general, urban parks are considered to be quality and important habitat for bumblebees $[16,20,22,38,66,68-70]$; this habitat type has average number of species compared to the other analyzed habitat types. There are differences in this group of territories. The quantity and quality of resources available to bees vary greatly among habitats, often attributable to the characteristics of the surrounding landscape [71]. For example, in Theophania park, the high species diversity was registered; there are 13 species. This park is located on the southern outskirts of the city and is adjacent to a large open area. In this time, some parks (Babi Yar park, Nyvky park, and KPI park) are isolated from other rich habitats; the 


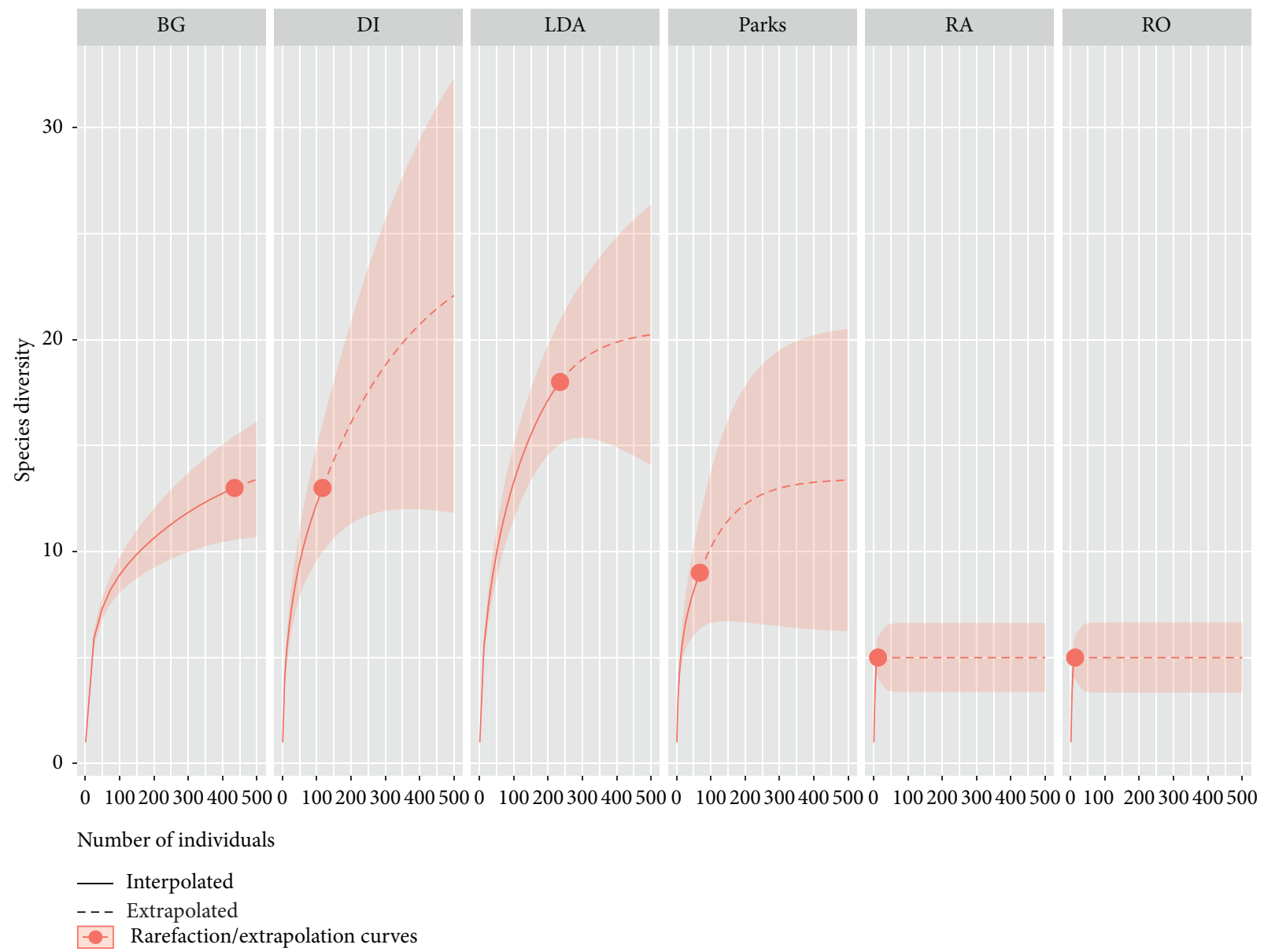

FIGURE 2: Estimated species richness of bumblebees collected at the investigated areas, using rarefaction analysis. BG-M. M. Gryshko NBG; DI-Dnipro River islands (Mutomets, Hydropark, Trukhaniv, and Zhukiv); LDA-least-disturbed areas within the city (Sviatoshynskyi forest park, Lysa Hora regional landscape park), Parks—urban parks (Nyvky, KPI Park, Babi Yar, Sovki, Theofania, Peremoha, and Partizans koi Slavy); RA-residential areas (Vinogradar and Teremki); and RO-roadsides (Akademika Zabolotnoho Str., Druzhby Narodiv Boulevard, Saperno-Slobidska Str., Zakrzewski Str., and Mayakovskoho Ave.).

arrival and survival of many species in these territories are probably quite difficult. Since the surrounding urban landscape determines the abundance of species [19], the expected number of species is six and the real number of species for KPI and Sovky is four. These parks are speciespoor and only the common species of bumblebees are regularly found here. Nevertheless, these urban parks are useable habitat surrounded by an inhospitable landscape [68]. As in other studies, severely disturbed habitats have low diversity of bees $[9,19,22,66,67]$, and only social species (bumblebees in particular) were found [69]. The expected number of species for the roadsides and residential areas groups tends to flatten at value five, although in our study these are from two to four species. Some roads are adjacent to habitats with a high diversity of bumblebees (for example, Druzhby Narodiv boulevard to M. M. Gryshko NBG, Saperno-Slobidska Str. to Lysa Hora RLP); nevertheless, only B. terrestris, B. lucorum, and B. lapidarius are found here. It is possible that an increase in the number of species is possible due to the periodic arrival of other species from the neighbouring much richer habitats [19].
Other types of sites are located within dense buildings and transport networks (Zakrevskogo Str. and Mayakovskoho Avenue) and here the arrival of species is possible from other green urban spaces. In residential areas, only rare individuals of common species were found here. At the same time, these types of habitats can provide a range of resources for bumblebees [68, 72]. Zhukiv and Muromets islands, Lysa Hora, Theofania park, and Botanical garden are distinguished by a large number of species, so they are of great importance in the conservation of bumblebees in the city.

\subsection{Distribution of Species of the Genus Bombus in Different} Urban Areas considering the Morphoecological Character "Length of Tongue". The group of short-tongued bumblebees was dominant, $83 \%$ of other groups. The group of mediumtongued bumblebees (14\% of all other groups) included six species, long-tongued insects included five species (3\% of other species), and kleptoparasites were represented by four species (2\% of other species, and they are short-tongued). The species compositions of studied territories varied by the 
TABLE 2: Species composition and distribution of bumblebees in habitat types of Kyiv.

\begin{tabular}{lcccc}
\hline & Species & \multicolumn{2}{c}{ Percentage of individuals (\%) } & Tongue length \\
& & All individuals & Females and males (without workers) & Lof habitat* \\
\hline $\mathbf{1}$ & B. argillaceus (Scopoli, 1763) & 0.5 & 0.19 & Long \\
$\mathbf{2}$ & B. bohemicus (Seidl, 1837) & 0.71 & 0.71 & Short (kleptoparasite) \\
$\mathbf{3}$ & B. campestris (Panzer, 1801) & 0.29 & 0.29 & Short (kleptoparasite) \\
$\mathbf{4}$ & B. hortorum (Linnaeus, 1761) & 1.8 & 0.42 & Long \\
$\mathbf{5}$ & B. humilis (Illiger, 1806) & 1 & 0.28 & Medium \\
$\mathbf{6}$ & B. hypnorum (Linnaeus, 1758) & 5.6 & 0.8 & Short \\
$\mathbf{7}$ & B. lapidarius (Linnaeus, 1758) & 27.6 & 1.4 & Short \\
$\mathbf{8}$ & B. lucorum (Linnaeus, 1761) & 46.15 & 3.4 & Short \\
$\mathbf{9}$ & B. terrestris (Linnaeus, 1758) & & 2.3 & Short \\
$\mathbf{1 0}$ & B. muscorum Linnaeus, 1758 & 0.1 & 0.1 & Long \\
$\mathbf{1 1}$ & B. pascuorum (Scopoli, 1763) & 8.22 & 1.4 & Medium \\
$\mathbf{1 2}$ & B. pratorum (Linnaeus, 1761) & 0.5 & 0.19 & Short \\
$\mathbf{1 3}$ & B. ruderarius (Müller, 1776) & 3.54 & 0.56 & Medium \\
$\mathbf{1 4}$ & B. rupestris (Fabricius, 1793) & 0.29 & 0.29 & 3 \\
$\mathbf{1 5}$ & B. soroeensis (Fabricius, 1777) & 1.29 & 0.37 & $1-6$ \\
$\mathbf{1 6}$ & B. subterraneus (Linnaeus, 1758) & 0.61 & 0.19 & Short (kleptoparasite) \\
$\mathbf{1 7}$ & B. sylvestris (Lepeletier, 1832) & 0.50 & 0.19 & Short \\
$\mathbf{1 8}$ & B. sylvarum (Linnaeus, 1761) & 0.80 & 0.71 & Long \\
$\mathbf{1 9}$ & B. vestalis (Geoffroy, 1785) & 0.36 & 0.36 & Short (kleptoparasite) \\
$\mathbf{2 0}$ & B. veteranus (Fabricius, 1793) & 0.14 & 0.14 & Medium \\
\hline
\end{tabular}

*Sample size: 2141 individuals. Type of habitat: 1-least-disturbed areas within the city; 2-urban parks; 3-botanical garden; 4-Dnipro River islands; 5-residential areas; and 6-roadsides.

TABle 3: Measures ANOVA of species richness of Bombus spp. in different types of urban habitat.

\begin{tabular}{lccccc}
\hline Test for equal means & SS & df & MS & F & $p$ \\
\hline Between groups & 7038.99 & 5 & 1407.8 & 3.127 & 0.011 \\
Within groups & 48627.6 & 108 & 450.255 & $\begin{array}{c}\text { Permutation } \\
p(n=99999)\end{array}$ \\
Total & 55666.6 & 113 & 0.008 & \multicolumn{2}{c}{-} \\
Levene's test for homogeneity of variance, from means \\
$\begin{array}{l}p=4.203 E-09 \\
\text { Levene's test, from medians } p=0,01297\end{array}$ \\
Kruskal-Wallis test for equal medians H $\left(\mathrm{chi}^{2}\right): 21.67, p=0.0002$ \\
\hline
\end{tabular}

core species of the most common: B. terrestris, B. lucorum, $B$. lapidarius, B. pascuorum, or B. hypnorum (Figure 3). For example, this species were most frequently observed in some other urban areas in Europe $[9,22,35,69,73,74]$.

Short-tongued species dominated at all areas and were the only bumblebees at several locations (Figure 2).

Only short-tongued species were found at residential areas (Teremky-1 and Vinogradar) and roadsides. At locations Babi Yar, Sovky, Sviatoshynskyi forest park, and Trukhaniv and Hydropark islands, the species diversity of bumblebees was low, with high share of short-tongued species. Kleptoparasites (B. bohemicus, B. campestris, $B$. rupestris, B. sylvestris, and B. sylvarum) preferred the bumblebee communities with high species diversity and density (Lysa Hora, Theophania park, botanical garden, and Muromets and Zhukiv islands). For example, the most common kleptoparasites were B. bohemicus and B. vestalis. That domination of most common and ecologically plastic species in communities is typical for cities $[7,8,16,73]$.

The diversity indicators also showed the uneven distribution of individuals of different species in bumblebee communities (Table 4).

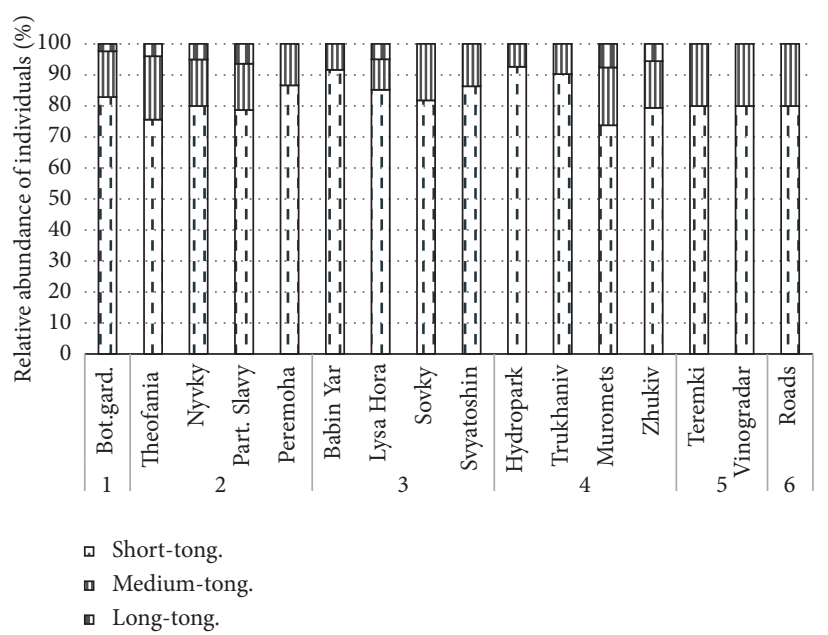

FIgURE 3: Ratio of morphoecological bumblebee groups on the model areas. 1: botanical garden: "BG Grishko"-M. M. Gryshko National Botanical Garden; 2: urban parks: Theofania-Theofania park; Nyvki-Nyvki park, Part. Slavy-Partizans'koi Slavy park, Peremoha-Peremoha park, KPI-KPI park; Babi Yar-Babi Yar park, Sovky-Sovky park; 3: least-disturbed areas within the city: Lysa Hora-Lysa Hora RLP; Svyatoshin-Sviatoshynskyi forest park; 4: Dnipro River islands: Hydropark-Hydropark island; Trukhaniv-Trukhaniv island; Muromets-Muromets island; Zhukiv-Zhukiv island; 5: residential areas: Teremki-Teremki residential area; and 6: roadsides. Notation of length of tongue: short-tong.-short-tongued species; medium-tong.-mediumtongued species; and long-tong.-long-tongued species of bumblebees.

Observed bumblebee species richness increased following the types of urban habitats and ranged between 14 species from the botanical garden, some sites "LDA," and 
TABLE 4: Species diversity indicators of bumblebee groups on the model territories.

\begin{tabular}{|c|c|c|c|c|}
\hline Model territories & Number of species & Number of individuals & Shannon's index & Equitability_J \\
\hline \multicolumn{5}{|l|}{ Botanical garden } \\
\hline 1: M. M. Gryshko NBG & 14 & 301 & 1.62 & 0.61 \\
\hline \multicolumn{5}{|l|}{ Urban parks } \\
\hline 2: Theofania park & 13 & 181 & 1.69 & 0.66 \\
\hline 3: Nyvky park & 6 & 120 & 1.37 & 0.85 \\
\hline 4: Babi Yar park & 5 & 114 & 1.28 & 0.92 \\
\hline 5: Partizans 'koi Slavy park & 6 & 127 & 1.32 & 0.83 \\
\hline 6: Peremoha park & 5 & 107 & 1.24 & 0.89 \\
\hline 7: KPI park & 4 & 51 & 1.24 & 0.93 \\
\hline 8: Sovky park & 4 & 104 & 1.07 & 0.77 \\
\hline \multicolumn{5}{|l|}{ Least-disturbed areas within the city } \\
\hline 9: Lysa Hora regional landscape park & 14 & 234 & 1.56 & 0.61 \\
\hline 10: Sviatoshynskyi forest park & 6 & 141 & 1.26 & 0.70 \\
\hline \multicolumn{5}{|l|}{ Dnipro River islands } \\
\hline 11: Hydropark island & 5 & 119 & 1.29 & 0.80 \\
\hline 12: Trukhaniv island & 7 & 134 & 1.16 & 0.65 \\
\hline 13: Muromets island & 12 & 126 & 1.72 & 0.69 \\
\hline 14: Zhukiv island & 12 & 132 & 1.58 & 0.66 \\
\hline \multicolumn{5}{|l|}{ Residential areas } \\
\hline 15: Teremki-1 residential area & 4 & 54 & 1.16 & 0.83 \\
\hline 16: Vinogradar residential area & 4 & 62 & 1.06 & 0.77 \\
\hline \multicolumn{5}{|l|}{ Roadsides } \\
\hline 17: Akademika Zabolotnoho Str. & 3 & 5 & 0.95 & 0.86 \\
\hline 18: Druzhby Narodiv Boulevard & 3 & 7 & 0.95 & 0.87 \\
\hline 19: Saperno-Slobidska Str. & 3 & 5 & 0.95 & 0.85 \\
\hline 20: Zakrevskogo str. & 3 & 9 & 0.94 & 0.85 \\
\hline 21: Mayakovskoho Ave. & 2 & 8 & 0.56 & 0.81 \\
\hline
\end{tabular}

some Dnipro islands upper to 2 species from some the roadside sites.

Maximum values of Shannon's index were noted for species-rich territories, such as GNBG, Theofania park, Lysa Hora, and Muromets and Zhukiv islands. Evenness index of bumblebee distribution reached high values $(\approx 0.8)$ at Nyvky and Partizans'koi Slavy and Sovky parks and residential areas, indicating the domination of certain species and the overall low species diversity. For example, B. pascuorum dominated in residential areas, while B. terrestris, B. lucorum, B. lapidarius, and (rarely) B. hypnorum or B. pascuorum dominated in parks with low species diversity.

Populations of long-tongued bumblebees are the most vulnerable to unfavorable conditions and tend to decline to the point of absence in their typical biotopes [36]. For example, the European populations of B. muscorum and B. sylvarum (a medium-tongued species) have become sparse in the last 50 years $[14,75]$. According to our data, these species similarly decline in urban environment. It should be noted that B. muscorum was recorded in GNBG only once in year 2013. In the next years of our study, no individual of that species (whether female, male, or worker) was found there. It possibly became locally extinct. Populations of $B$. argillaceus and $B$. hortorum were relatively more stable, but not numerous (no more than two females or males were seen on location each year).

The mean number of workers is known to vary in families of different species, though the size of bumblebee family is shown to depend on the latitude and phenological characteristics of biotope $[34,76]$. As a rule, there are 100 to 200 individuals in a bumblebee family living at middle latitudes [33]. Families of certain species (B. muscorum and $B$. ruderarius) are smaller, with under a hundred working individuals. In contrast, there are more than 300 workers in families of such species as B. lucorum, B. terrestris, B. lapidarius, and B. hypnorum. Unsurprisingly, their representatives dominate the communities. It is, though, important to note that families of $B$. argillaceus can consist of nearly 500 individuals, and our data points to a small-sized urban population of that species. Possibly, the nonnumerous families are an adaptation to unstable conditions. Sustaining such families requires fewer provisions (nectar, pollen). However, the instability of urban plant associations and the possibility of loosing workers to fires or chemical pollution depress the family's overall life activity.

3.3. Relations in Species Composition of Bumblebees and Flowering Plants in Urban Habitats. There is a positive relationship between the richness of flower resources and the diversity of pollinators at local and landscape level $[6,37,53,77-80]$. Diverse and rich communities attract a much diverse pollinator fauna [78, 79]. Variation in the pollinator assemblage of particular species can be caused by the variation in the plant community [3]. In the studied urban areas, we also found a positive relationship between the number of plant species and the diversity of bumblebees (Figures 4(a) and 4(b)). 
Bumblebee species richness was positively related to the final number of flowering plant species, but there are can be different causes, like a fragmentation, type of habitat, and historical conditions for the communities development of bumblebees [7, 15, 19, 21, 23, 35, 76, 77].

Using cluster analysis, we found the differences in species composition of bumblebees and flowering plants of studied areas. Some habitat types were similarly grouped by the results of analysis on diversity of bumblebees and of plants. That, to some extent, is explained by the relationship and dependence between bumblebees and flowering plants (Figure 5 and Figure 6), which has also been shown in some studies [37, 76, 78-81].

The grouping of urban habitats in our study is explained by the predominance of common and numerous shorttongued species and, to a lesser extent, of medium-tongued bumblebees and long-tongued bumblebees especially. As a rule, generalist bumblebees are common [19,68], and the distribution of these species did not differ significantly between the types of habitats in other studies [19]. In our study, the groups habitats "LDA" and "DI" are the leastdisturbed, and bumblebee species compositions of this groups were similar; at the same time botanical garden and urban parks have some differences (Figure 6). Also in some studies, it has been shown that natural and seminatural habitats were the most suitable for bees $[67,77]$ and most of them had significant similarities [67]. The similarity of the species composition of bumblebees in this habitats is explained by the presence of long-tongued species (B. muscorum and B. subterraneus), some medium-tongued species (B. humilis, B. ruderarius, B. veteranus, and $B$. sylvarum), and most inquiline species. Specialist bees (including cleptoparasitic species) have lower adaptation capacity to the new environmental conditions [82]. These species are not common in urban habitat, their presence in communities can explain the similarity of sites [21, 69, 70].

There is high diversity of bumblebees only in Theofania park among the group of urban parks. Differences in the species composition of bumblebees between the same types of habitats are also known and some large parks differ highly in diversity [68]. In Nyvky park, in addition to the most common species, the bumblebee species composition included $B$. argillaceus that explains the similarity of bumblebee species composition in all urban parks and other habitats with high diversity of bumblebees.

The plant diversity and floral abundance allow for an increase in the abundance and richness of wild bees in different habitat types $[62,64]$.

The similarity of plant composition in LDA and BG is explained by some native common species (Cytisus spp., Genista tinctoria L., Knautia arvensis, Knautia arvensis (L.) Coult, Melilotus officinalis (L.) Lam., Origanum vulgare L., Pulmonaria spp., and Scilla bifolia L.).

The group of habitats DI has some variation in the composition of plants. There are Filipendula ulmaria (L.) Maxim., Inula britannica (L.), and Rhinanthus vernalis (N.W. Zinger) Schischk only in this type of habitat.

The species composition of plants in the parks is characterized by above-average diversity compared to roadsides and residential areas, but there are common ornamental plants and low-diversity native plants. Most parks have ornamental plants, which are commonly used in planting in residential areas. The roadsides and residential biotopes were grouped together because the local species diversity of bumblebees and density of even the most common species were very low-only widespread species B. hypnorum, B. pascuorum, B. lapidarius, B. lucorum, and $B$. terrestris were found there. The plant diversity was rather poor, including a limited variety of trees and grasses and green lawns, sometimes with clovers and dandelions. However, there are differences in the composition of ornamental flowering plants between residential areas and roadsides. Low plant diversity in residential areas is typical for many cities $[21,64,70]$. The residential areas of Teremki1 and Vinogradar are not located close to each other, but their range of ornamental plants was quite similar (Centaurea spp., Hosta spp., Tilia spp., and Aesculus spp.), although Dahlia spp. and Malva species are only in Teremki.

\subsection{Angiosperm Preferences of Bumblebees in Urban} Habitats. The richness of floral resources is an important factor determining the presence of different morphological groups in the bumblebee community $[3,54,78,81]$. Overall, we found bumblebees on plants of more than 60 species of the families Apocynaceae, Asteraceae, Boraginaceae, Caprifoliaceae, Fabaceae, Lamiaceae, Malvaceae, Rosaceae, Plantaginaceae, and Salicaceae (Figure 7). GNBG, Lysa Hora, Theofania, and some islands of Dnipro River all boasted a high diversity of the pollinators and their floral resources. The least studied diversity was found in residential areas and roadsides.

Overall, 30 plant species were more preferable for bumblebees in urban environment (number of interactions more than 30 per plant species-Rhinanthus vernalis, Echium vulgare, Cirsium arvense, Trifolium pratensis, Spirea spp., Tilia spp., Trifolium repens, Centaurea jacea, Aesculus hippocastanum, Vicia spp., Solidago canadensis, Symphytum officinale L., Eryngium planum, Lamium spp., Betonica officinalis, Hosta spp., Securigera varia, Dahlia spp., Malus spp., Cephalaria gigantea, Inula britannica, Knautia arvensis, Gypsophila spp., Asclepias syriaca, and Pulmonaria spp.)

The bumblebees' preferences of plant species depended on the type of area and presence of floral resources. In early spring, females mostly preferred flowers of the genera Corydalis, Scilla, Pulmonaria, Salix, Malus, and Prunus. The special role and attractivity of Salix spp. and Prunus in the feeding of bumblebees was noted in some other studies $[83,84]$. The workers were frequently recorded on blooming plants Tilia cordata Mill., Aesculus hippocastanum L., and the invasive species in Ukraine Solidago canadensis and Asclepias syriaca. It should be noted that, as in some other studies [85-87], we found dead bumblebees under the tree of Tilia tomentosa Moench. The causes of death of bumblebees are obscure [85-87], but it is probably desirable to use other nectar- and pollen-providing plants in urban landscaping. The bumblebees of Dnipro River islands mostly were recorded on blooming plants of Rhinanthus vernalis. Such species as 


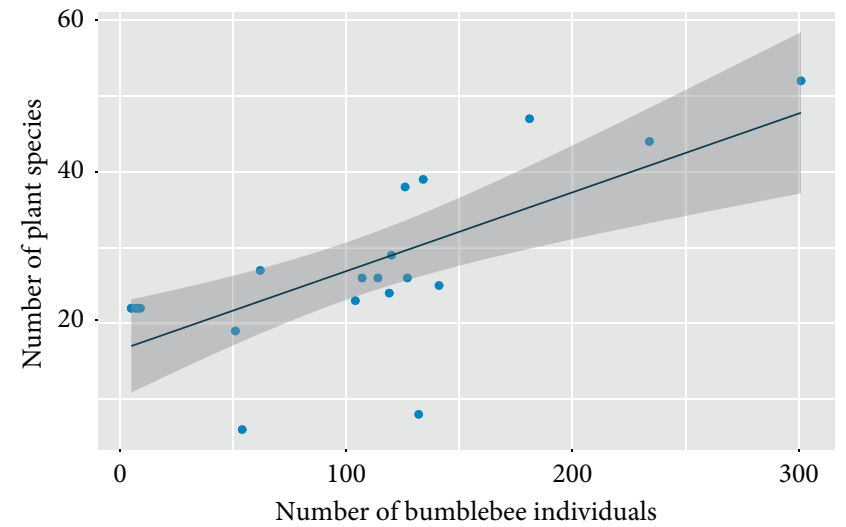

(a)

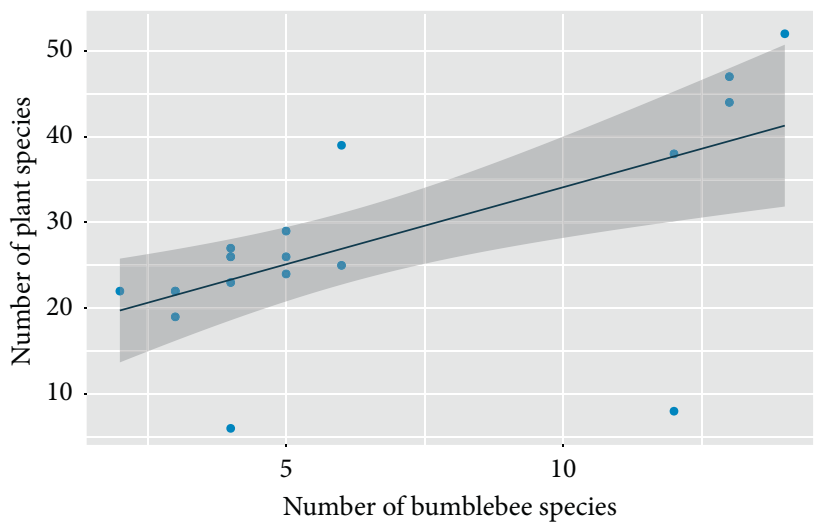

(b)

Figure 4: (a) and (b) Effects of the number of flowering plant species on the number species and individuals of Bombus spp. (a) $R^{2}=0.5$, $p=0.0003$. (b) $R^{2}=0.4, p=0.002$.

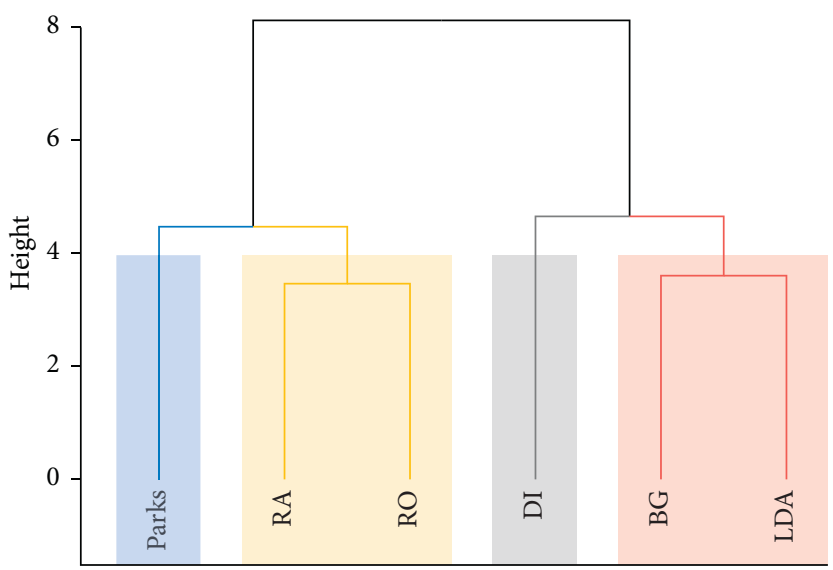

Figure 5: Cluster dendrogram derived from the cluster analysis of similarity of the angiosperm species composition in urban habitats of Kyiv, Ukraine. BG-M. M. Gryshko NBG; DI-Dnipro River islands (Hydropark; Trukhaniv; Zhukiv); LDA-least-disturbed areas within the city (Sviatoshynskyi forest park and Lysa Hora regional landscape park); Parks—urban parks (Nyvky, KPI Park, Babi Yar, Sovki, Theofania, Peremoha, and Partizans'koi Slavy park); RA—residential areas (Vinogradar and Teremki); RO—roadsides (Akademika Zabolotnoho Str., Druzhby Narodiv Boulevard, Saperno-Slobidska Str., Zakrevskogo Str., and Mayakovskoho Ave.).

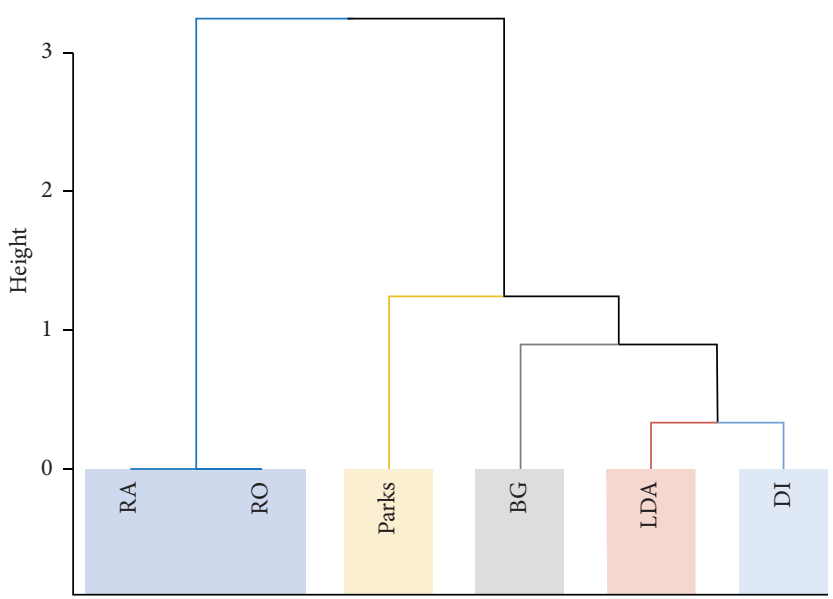

FIgURE 6: Cluster dendrogram derived from the cluster analysis of bumblebee species composition in urban habitats of Kyiv, Ukraine. Notation is given in Figure 5. 


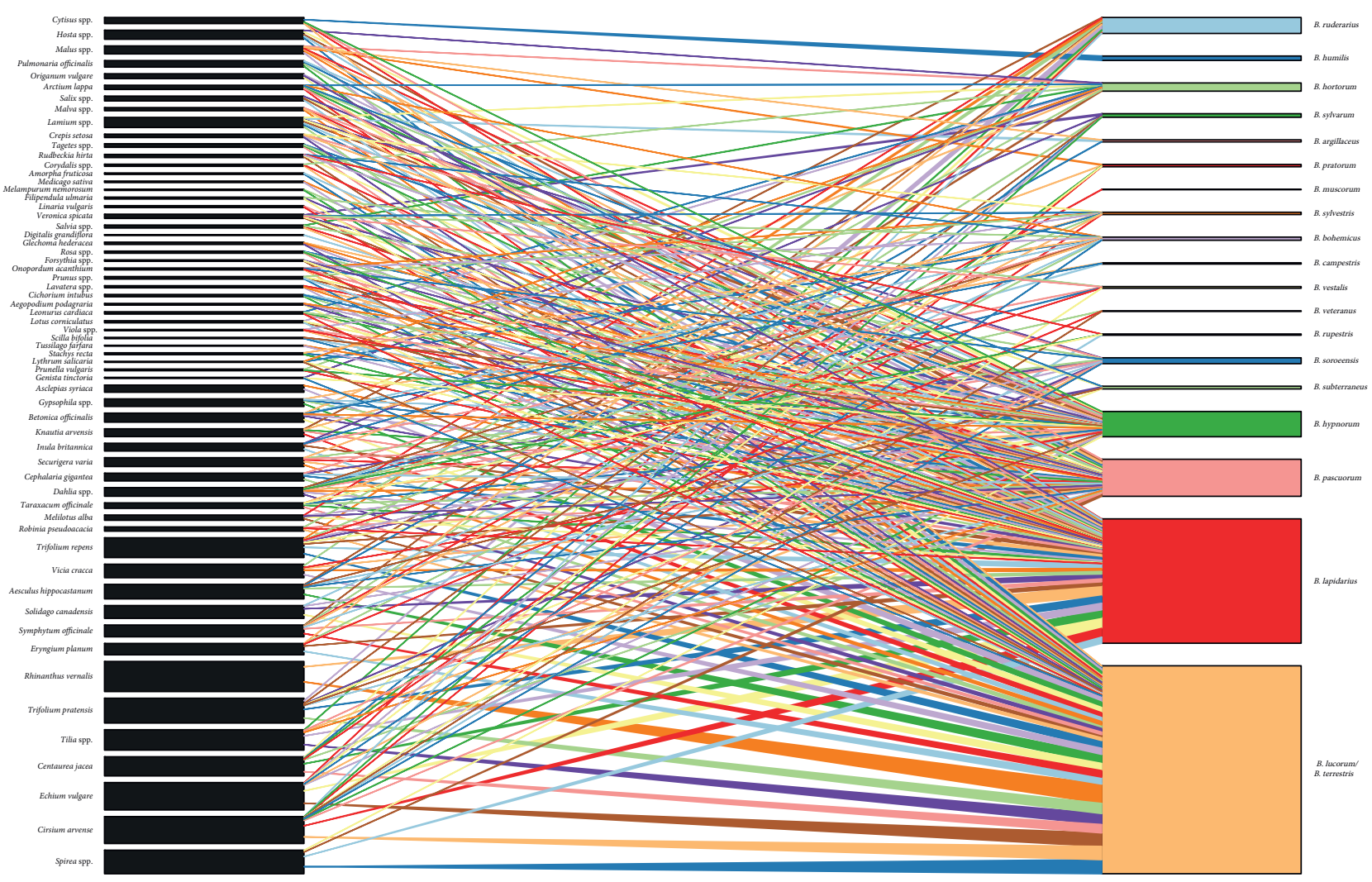

Figure 7: Relationship between bumblebees and the plants they visit. Bombus species in blue, plant species in green. Width of horizonal bars denotes interaction frequency of each species. Gray bar width denotes interaction strength.

Symphytum officinale, Cirsium arvense, and Trifolium spp. attracted bumblebees in all urban habitats type. In residential areas, bumblebees mostly foraged on plants of Trifolium spp., which usually profusely bloom near houses or at lawns. Protected species of bumblebees were found on widely distributed plants: B. argillaceus on Lamium purpureum and B. muscorum on Symphytum officinale. B. humilis, which is quite rare in Europe, was recorded in Kyiv in Lysa Hora RLP and Theofania park and only on Cytisus Desf. plants.

The ornamental plants play a significant role as the floral resource of bumblebees in urban conditions $[63,74]$. There were various angiosperms in urban parks in Kyiv, which were rich in nectar and pollen and attracted bumblebees: Rudbeckia spp., Spiraea spp., Tagetes ssp., Malva spp., Hosta spp., Digitalis spp., and Rosa spp. [88]. Numerous shorttongued bumblebees were seen in all habitat types with blooming bushes of Spiraea japonica. In general, Spiraea plants were attractive to the short-tongued $B$. lapidarius, $B$. lucorum, and B. terrestris, to the medium-tongued B. pascuorum, and in rare cases, to members of other morphoecological groups (B. hortorum and B. ruderarius).

Plant diversity has degraded at most studied areas. For example, plant associations of forested areas (Sviatoshynskyi forest park, Partizans'koi Slavy park, Babi Yar park, and Peremoha park) were not advantageous for bumblebees after the blooming of a number of tree species and spring ephemeroids (Salix, Pulmonaria, and Corydalis.). The open and wooded meadows provide more floral resources during summer, but not enough in early spring when only Salix plants are blooming. The urban environment, particularly parks, is thought to provide enough nesting and floral resources for many bumblebee species [20]. In Kyiv, such resources were found at Lysa Hora, Theofania, and GNBG. These territories are large, with variety of habitats and high diversity of native, ornamental, and introduced plants. According to our data, the diversity of wild bees of GNBG was also significant [89]. In most other parks and natural areas, frequent mowing and burning of grass have a negative impact on the functioning and survival of bumblebee populations. In parks and residential areas, along roadsides, the list of angiosperms preferred by bumblebees was rather short. In such habitats' type, there is no gradual succession of blooming plants; thus, the areas should be considered additional or temporary refugiums for the insects.

\section{Conclusion}

The diversity of bumblebees in the studied region was high, but some species known in 1930 have already disappeared from the city. The short-tongued bumblebee species were the majority of the ecologically plastic groups of bumblebees and the core of urban bumblebee communities. The species 
diversity of the more specialized average- and long-tongued bumblebees was lower, and they make up only $3 \%$ of total population of bumblebees in city.

Five bumblebee species were common at different urban model areas: B. terrestris, B. lucorum, B. lapidarius, $B$. pascuorum, and $B$. hypnorum. Single individuals of $B$. argillaceus, $B$. humilis, B. muscorum, $B$. pratorum, and $B$. veteranus were found only at a few areas; the numbers of their workers and reproductive individuals were also low.

High species diversity of bumblebees was recorded in some types of urban habitat (M. M. Gryshko National Botanical Garden, least-disturbed areas within the city-only in Lysa Hora RLP, some Dnipro River islands-Muromets and Zhukiv, and among the group of urban parks-only in Theofania). These territories were the most attractive for insects because the spatial distribution of bumblebees depends on the category of area and angiosperm composition.

The environment was more hostile to bumblebees at roadsides and residential areas, where the species composition of bumblebees was composed only of the most common species.

Plants of the families Asteraceae, Fabaceae, Lamiaceae, Rosaceae, and Salicaceae represented the main urban floral resources of bumblebees in the city. The ornamental and ruderal plants also provided significant feeding resources for bumblebees in parks and residential areas.

Findings of rare and endangered bumblebee species (B. argillaceus, B. muscorum, B. sylvarum, and B. humilis) in least-disturbed areas within the city, some parks, and the botanical garden indicate the high specificity of such habitats' type and the need to protect them from overuse for conservation and restoration of bumblebee populations.

\section{Data Availability}

The data used to support the findings of this study are included within the Supplementary Materials file.

\section{Conflicts of Interest}

The author declares no conflicts of interest regarding the publication of this paper.

\section{Acknowledgments}

The author would like to express her gratitude to her supervisor, Dr. Sci., Prof. Vladimir G. Radchenko (Institute for Evolutionary Ecology of the National Academy of Sciences of Ukraine), who guided her throughout this study. Special thanks are due to Maxim V. Netsvetov (Institute for Evolutionary Ecology of the National Academy of Sciences of Ukraine), who supported her and helped with data processing. The research leading to this publication has received funding from the State Budget Program "The Support of the Priority Research Areas Development of Ukraine, KPKVK 6541230."

\section{Supplementary Materials}

Supplementary file contains data and information about species composition, distribution, and trophic relationships of bumblebees (Supplementary Materials)

\section{References}

[1] I. B. Konovalova, "The bumble bees of Ukraine: species distribution and floral preferences," Psyche: A Journal of Entomology, vol. 2010, Article ID 819740, 10 pages, 2010.

[2] P. Rasmont, M. Franzén, T. Lecocq et al., Climatic risk and distribution atlas of European bumblebees, vol. 10, pp. 1-236, Pensoft Publishers, Sofia, Bulgaria, 2015.

[3] A. Lázaro, A. Jakobsson, and Ø. Totland, "How do pollinator visitation rate and seed set relate to species' floral traits and community context?" Oecologia, vol. 173, no. 3, pp. 881-893, 2013.

[4] S. E. McGregor, Insect Pollination of Cultivated Crop Plants, Vol. 496, Agricultural Research Service, Washington, D.C., USA, 1976.

[5] R. Bommarco, O. Lundin, H. G. Smith, and M. Rundlöf, "Drastic historic shifts in bumble-bee community composition in Sweden," Proceedings of the Royal Society B: Biological Sciences, vol. 279, no. 1727, pp. 309-315, 2012.

[6] C. Carvell, "Habitat use and conservation of bumblebees (Bombus spp.) under different grassland management regimes," Biological Conservation, vol. 103, no. 1, pp. 33-49, 2002.

[7] Ú. Fitzpatrick, T. E. Murray, R. J. Paxton et al., "Rarity and decline in bumblebees-a test of causes and correlates in the irish fauna," Biological Conservation, vol. 136, no. 2, pp. 185-194, 2007.

[8] D. Goulson, E. Nicholls, C. Botías, and E. L. Rotheray, "Bee declines driven by combined stress from parasites, pesticides, and lack of flowers," Science, vol. 347, no. 6229, p. 1255957 , 2015.

[9] B. Gunnarsson and L. M. Federsel, "Bumblebees in the city: abundance, species richness and diversity in two urban habitats," Journal of Insect Conservation, vol. 18, no. 6, pp. 1185-1191, 2014.

[10] A. Kosior, W. Celary, P. Olejniczak et al., "The decline of the bumble bees and cuckoo bees (hymenoptera: apidae: bombini) of western and central Europe," Oryx, vol. 41, no. 1, pp. 79-88, 2007.

[11] P. H. Williams and J. L. Osborne, "Bumblebee vulnerability and conservation world-wide," Apidologie, vol. 40, no. 3, pp. 367-387, 2009.

[12] A. Nieto, S. P. M. Roberts, J. Kemp et al., "European red list of bees," Publication Office of the European Union, vol. 2, no. 3, p. 4, Luxembourg. Europe, 2014.

[13] S. A. Cameron, J. D. Lozier, J. P. Strange et al., "Patterns of widespread decline in North American bumble bees," Proceedings of the National Academy of Sciences, vol. 108, no. 2, pp. 662-667, 2011.

[14] B. Darvill, J. S. Ellis, G. C. Lye, and D. Goulson, "Population structure and inbreeding in a rare and declining bumblebee, Bombus muscorum (Hymenoptera: apidae)," Molecular Ecology, vol. 15, no. 3, pp. 601-611, 2006.

[15] I. Diaz-Forero, V. Kuusemets, M. Mänd, A. Liivamägi, T. Kaart, and J. Luig, "Influence of local and landscape factors on bumblebees in semi-natural meadows: a multiple-scale study in a forested landscape," Journal of Insect Conservation, vol. 17, no. 1, pp. 113-125, 2013. 
[16] N. I. Eremeeva and D. V. Sushchev, "Structural changes in the fauna of pollinating insects in urban landscapes," Russian Journal of Ecology, vol. 36, no. 4, pp. 259-265, 2005.

[17] L. Fortel, M. Henry, L. Guilbaud et al., "Decreasing abundance, increasing diversity and changing structure of the wild bee community (Hymenoptera: anthophila) along an urbanization gradient," PLoS One, vol. 9, no. 8, p. e104679, 2014.

[18] J. T. Kerr, A. Pindar, P. Galpern et al., "Climate change impacts on bumblebees converge across continents," Science, vol. 349, no. 6244, pp. 177-180, 2015.

[19] K. Ahrne, J. Bengtsson, and T. Elmqvist, "Bumble bees (Bombus spp) along a gradient of increasing urbanization," PloS One, vol. 4, no. 5, 2009.

[20] D. M. Hall, G. R. Camilo, R. K. Tonietto et al., "The city as a refuge for insect pollinators," Conservation Biology, vol. 31, no. 1, pp. 24-29, 2017.

[21] K. C. Matteson and G. A. Langellotto, "Determinates of inner city butterfly and bee species richness," Urban Ecosystems, vol. 13, no. 3, pp. 333-347, 2010.

[22] P. Michołap, A. Sikora, M. Kelm, and M. Sikora, "Variability of bumblebee communities (Apidae, Bombini) in urban green areas," Urban Ecosystems, vol. 20, no. 6, pp. 1339-1345, 2017.

[23] A. J. Bates, J. P. Sadler, A. J. Fairbrass, S. J. Falk, J. D. Hale, and T. J. Matthews, "Changing bee and hoverfly pollinator assemblages along an urban-rural gradient," PloS One, vol. 6, no. 8, p. e23459, 2011.

[24] N. E. Miller-Struttmann, J. C. Geib, J. D. Franklin et al., "Functional mismatch in a bumble bee pollination mutualism under climate change," Science, vol. 349, no. 6255, pp. 1541-1544, 2015.

[25] B. Borrell and H. Krenn, "Nectar feeding in long-proboscid insects," Ecology and Biomechanics: A Mechanical Approach to the Ecology of Animals and Plants, CRC Taylor and Francis, Boca Raton, Florida, pp. 85-212, 2006.

[26] A. D. Brian, "Differences in the flowers visited by four species of bumble-bees and their causes," The Journal of Animal Ecology, vol. 26, no. 1, pp. 71-98, 1957.

[27] V. G. Radchenko and Y. A. Pesenko, Biology of Bees (Hymenoptera, Apoidea), Zoological Institute of the Russian Academy of Sciences, Saint-Petersburg, Russia, 1994.

[28] L. D. Harder, "Morphology as a predictor of flower choice by bumble bees," Ecology, vol. 66, no. 1, pp. 198-210, 1985.

[29] L. D. Harder, "Measurement and estimation of functional proboscis length in bumblebees (Hymenoptera: apidae)," Canadian Journal of Zoology, vol. 60, no. 5, pp. 1073-1079, 1982.

[30] D. W. Inouye, "The effect of proboscis and corolla tube lengths on patterns and rates of flower visitation by bumblebees," Oecologia, vol. 45, no. 2, pp. 197-201, 1980.

[31] L. Pellissier, J.-N. Pradervand, P. H. Williams, G. Litsios, D. Cherix, and A. Guisan, "Phylogenetic relatedness and proboscis length contribute to structuring bumblebee communities in the extremes of abiotic and biotic gradients," Global Ecology and Biogeography, vol. 22, no. 5, pp. 577-585, 2013.

[32] G. H. Pyke, D. W. Inouye, and J. D. Thomson, "Local geographic distributions of bumble bees near Crested Butte, Colorado: competition and community structure revisited," Environmental Entomology, vol. 41, no. 6, pp. 1332-1349, 2012.

[33] V. G. Radchenko, Biology of the Bumblebee Colony, p. 55, Kiev: Zoological Institute National Academy of Sciences of Ukraine, Kiev, Ukraine, 1989.
[34] E. Ranta and H. Lundberg, "Resource partitioning in bumblebees: the significance of differences in proboscis length," Oikos, vol. 35, no. 3, pp. 298-302, 1980.

[35] D. Goulson and B. Darvill, "Niche overlap and diet breadth in bumblebees; are rare species more specialized in their choice of flowers?" Apidologie, vol. 35, no. 1, pp. 55-63, 2004.

[36] D. Goulson, M. E. Hanley, B. Darvill, J. S. Ellis, and M. E. Knight, "Causes of rarity in bumblebees," Biological Conservation, vol. 122, no. 1, pp. 1-8, 2005.

[37] C. Carvell, P. Westrich, W. R. Meek, R. F. Pywell, and M. Nowakowski, "Assessing the value of annual and perennial forage mixtures for bumblebees by direct observation and pollen analysis," Apidologie, vol. 37, no. 3, pp. 326-340, 2006.

[38] I. B. Konovalova, "Urban communities of bumble bees (Hymenoptera: apidae: Bombus) and environmental conditions need for their existence," Scientific Proceedings of Belgorod State University, Series Natural Sciences, vol. 3, pp. 81-89, 2009.

[39] A. G. Lebedev, "A contribution to the knowledge of the fauna and ecology of insect pollinator of plants. I. The bees of the environs of Kiev," Proceedings of the Academy of Sciences of the Ukrainian SSR, vol. 1, pp. 13-50, 1933.

[40] Y. A. Muzichenko, "A contribution to the knowledge of the fauna and ecology of insects pollinating fruit trees. Pt. I," Proceedings of the Institute of Zoology and Biology of the Academy of Sciences of the Ukrainian SSR, vol. 9, no. 3, pp. 101-155, 1936.

[41] Y. A. Muzichenko, "A contribution to the knowledge of the fauna and ecology of insects pollinating fruit trees. Pt. II," Proceedings of the Institute of Zoology and Biology of the Academy of Sciences of the Ukrainian SSR, vol. 14, no. 4, pp. 197-229, 1937.

[42] A. N. Nevkryta, "Insect pollinators of cultivated cucurbitaceous plants," Kiev: Proceedings of the Academy of Sciences of the Ukrainian SSR, pp. 1-92, 1953.

[43] O. M. Nevkryta, "A contribution to the knowledge of insect pollinators of sweet cherry and sour-cherry trees in the Ukraine," Proceedings of the Zoological Museum of the Academy of Sciences of the Ukrainian SSR, vol. 28, pp. 49-61, 1957.

[44] Y. P. Didukh and U. M. Aloshkina, Biotopes of Kyiv, K: NaUKMA, Ahrar Media Hrup, Kyriv, Ukrania, 2012.

[45] E. V. Hagen, "Hummeln," in Naturführer, Neumann-Neudamm, Melsungen 221 1994, Naturbuch Verlag, Saarbrücken, Germany, 4th edition320 pages, Naturbuch Verlag, Saarbrücken, Germany, 1986.

[46] Ø. Hammer, D. A. T. Harper, and P. D. Ryan, "PAST: paleontological statistics software package for education and data analysis," Palaeontologia Electronica, vol. 4, no. 1, pp. 1-9, 2001.

[47] A. Løken, "Studies on scandinavian bumble bees (Hymenoptera, Apidae)," Norwegian Journal of Entomology, vol. 20, no. 1, pp. 1-218, 1973.

[48] A. Løken, "Scandinavian species of the genus psithyrus lepeletier (hymenoptera: apidae)," Scandinavian Society of Entomology, vol. 23, p. 16438, 1984.

[49] S. F. Sakagami, "Specific differences in the bionomic characters of bumblebees: a comparative review (with 4 textfigures)," Hokkaido University, vol. 20, no. 3, pp. 390-447, 1976.

[50] Y. A. Pesenko, Principles and Methods of Quantitative Analysis in Faunistic Researches, p. 288, Moskva, Russia, Nauka, 1982. 
[51] M. Edwards and M. Jenner, Field Guide to the Bumblebees of Great Britain \& Ireland, Ocelli Ltd, Bengaluru, India, 2005.

[52] I. A. Akimov and V. Radchenko, Red Data Book of Ukraine. Animals, p. 600, Kyiv: Global Consulting, Kyiv, Ukraine, 2009.

[53] E. E. Crone and N. M. Williams, "Bumble bee colony dynamics: quantifying the importance of land use and floral resources for colony growth and queen production," Ecology Letters, vol. 19, no. 4, pp. 460-468, 2016.

[54] R. F. Pywell, E. A. Warman, C. Carvell et al., "Providing foraging resources for bumblebees in intensively farmed landscapes," Biological Conservation, vol. 121, no. 4, pp. 479-494, 2005.

[55] S. Wolf, M. Rohde, and R. F. A. Moritz, "The reliability of morphological traits in the differentiation ofBombus terrestrisandB. lucorum (Hymenoptera: apidae)," Apidologie, vol. 41 , no. 1, pp. 45-53, 2010.

[56] A. E. Magurran, Measuring Biological Diversity, John Wiley \& Sons, Hoboken, NJ, USA, 2013.

[57] C. F. Dormann, "Using bipartite to describe and plot twomode networks in R," 2019.

[58] P. H. Williams, A. Byvaltsev, C. Sheffield, and P. Rasmont, "Bombus cullumanus-an extinct European bumblebee species?” Apidologie, vol. 44, no. 2, pp. 121-132, 2013.

[59] C. S. Sheffield, A. Pindar, L. Packer, and P. G. Kevan, "The potential of cleptoparasitic bees as indicator taxa for assessing bee communities," Apidologie, vol. 44, no. 5, pp. 501-510, 2013.

[60] O. Diestelhorst and K. Lunau, "Ergänzungen zur Bienenfauna des Botanischen Gartens der Universität Düsseldorf," Acta Biologica Benrodis, vol. 14, pp. 97-105, 2007.

[61] S. Dötterl and P. Harmann, "Die Bienenfauna des ÖkologischBotanischen Gartens der Universität Bayreuth," Nachr Bl bayerEnt, vol. 52, no. 1/2, pp. 2-20, 2003.

[62] N. M. Mazzeo and J. P. Torretta, "Wild bees (hymenoptera: apoidea) in an urban botanical garden in buenos aires, Argentina," Studies on Neotropical Fauna and Environment, vol. 50, no. 3, pp. 182-193, 2015.

[63] A. Sikora and M. Kelm, "Flower preferences of the wrockaw botanical garden bumblebees (Bombus spp.)," Journal of Apicultural Science, vol. 56, no. 2, pp. 27-36, 2012.

[64] R. Winfree, "The conservation and restoration of wild bees," Annals of the New York Academy of Sciences, vol. 1195, no. 1, pp. 169-197, 2010.

[65] A. C. Martins, R. B. Gonçalves, and G. A. R. Melo, "Changes in wild bee fauna of a grassland in Brazil reveal negative effects associated with growing urbanization during the last 40 years," Zoologia (Curitiba), vol. 30, no. 2, pp. 157-176, 2013.

[66] D. Tommasi, A. Miro, H. A. Higo, and M. L. Winston, "Bee diversity and abundance in an urban setting," The Canadian Entomologist, vol. 136, no. 6, pp. 851-869, 2004.

[67] M. Á. Collado, D. Sol, and I. Bartomeus, "Bees use anthropogenic habitats despite strong natural habitat preferences," Diversity and Distributions, vol. 25, no. 6, pp. 924-935, 2019.

[68] Q. S. McFrederick and G. LeBuhn, "Are urban parks refuges for bumble bees Bombus spp. (Hymenoptera: apidae)?” Biological Conservation, vol. 129, no. 3, pp. 372-382, 2006.

[69] W. Banaszak-Cibicka and M. Żmihorski, "Wild bees along an urban gradient: winners and losers," Journal of Insect Conservation, vol. 16, no. 3, pp. 331-343, 2012.

[70] E. D. Fetridge, J. S. Ascher, and G. A. Langellotto, "The bee fauna of residential gardens in a suburb of New York city (hymenoptera: apoidea)," Annals of the Entomological Society of America, vol. 101, no. 6, pp. 1067-1077, 2008.
[71] C. Kremen, N. M. Williams, and R. W. Thorp, "Crop pollination from native bees at risk from agricultural intensification," Proceedings of the National Academy of Sciences, vol. 99, no. 26, pp. 16812-16816, 2002.

[72] J. L. Hopwood, "Roadsides and pollinator conservation: the relationship between native bees and floral diversity," Dissertation, University of Kansas, Lawrence, KS, USA, 2006.

[73] I. Hanski, "Structure in bumblebee communities," in Annales Zoologici Fennici, pp. 319-326, JSTOR, New York, NY, USA, 1982.

[74] A. Sikora, P. Michołap, and M. Sikora, "What kind of flowering plants are attractive for bumblebees in urban green areas?" Urban Forestry \& Urban Greening, vol. 48, Article ID 126546, 2020.

[75] J. S. Ellis, M. E. Knight, B. Darvill, and D. Goulson, "Extremely low effective population sizes, genetic structuring and reduced genetic diversity in a threatened bumblebee species, Bombus sylvarum (Hymenoptera: apidae)," Molecular Ecology, vol. 15, no. 14, pp. 4375-4386, 2006.

[76] I. Steffan-Dewenter, U. Münzenberg, C. Bürger, C. Thies, and T. Tscharntke, "Scale-dependent effects of landscape context on three pollinator guilds," Ecology, vol. 83, no. 5, pp. 1421-1432, 2002.

[77] L. A. Burkle, J. C. Marlin, and T. M. Knight, "Plant-pollinator interactions over 120 years: loss of species, co-occurrence, and function," Science, vol. 339, no. 6127, pp. 1611-1615, 2013.

[78] A. Ebeling, A.-M. Klein, J. Schumacher, W. W. Weisser, and T. Tscharntke, "How does plant richness affect pollinator richness and temporal stability of flower visits?" Oikos, vol. 117, no. 12, pp. 1808-1815, 2008.

[79] S. J. Hegland and L. Boeke, "Relationships between the density and diversity of floral resources and flower visitor activity in a temperate grassland community," Ecological Entomology, vol. 31, no. 5, pp. 532-538, 2006.

[80] C. Westphal, I. Steffan-Dewenter, and T. Tscharntke, "Mass flowering crops enhance pollinator densities at a landscape scale," Ecology Letters, vol. 6, no. 11, pp. 961-965, 2003.

[81] A. D. Vaudo, J. F. Tooker, C. M. Grozinger, and H. M. Patch, "Bee nutrition and floral resource restoration," Current Opinion in Insect Science, vol. 10, pp. 133-141, 2015.

[82] L. Packer, A. Zayed, J. C. Grixti et al., "Conservation genetics of potentially endangered mutualisms: reduced levels of genetic variation in specialist versus generalist bees," Conservation Biology, vol. 19, no. 1, pp. 195-202, 2005.

[83] L. Moquet, C. Mayer, D. Michez, B. Wathelet, and A.-L. Jacquemart, "Early spring floral foraging resources for pollinators in wet heathlands in Belgium," Journal of Insect Conservation, vol. 19, no. 5, pp. 837-848, 2015.

[84] N. E. Raine and L. Chittka, "Mengen der nektarerzeugung bei 75 von hummeln besuchten blumenarten in einem deutschen pflanzenbestand (Hymenoptera: apidae: Bombus terrestris)," Entomologia Generalis, vol. 30, no. 2, pp. 191-192, 2007.

[85] A.-L. Jacquemart, L. Moquet, P. Ouvrard, J. Quetin-Leclercq, M.-F. Hérent, and M. Quinet, "Tilia trees: toxic or valuable resources for pollinators?” Apidologie, vol. 49, no. 5, pp. $538-550,2018$.

[86] H. Koch and P. C. Stevenson, "Do linden trees kill bees? Reviewing the causes of bee deaths on silver linden (Tilia tomentosa)," Biology Letters, vol. 13, no. 9, p. 20170484, 2017.

[87] C. Lande, S. Rao, J. T. Morré et al., "Linden (Tilia cordata) associated bumble bee mortality: metabolomic analysis of nectar and bee muscle," PLoS One, vol. 14, no. 7, 2019.

[88] V. Radchenko and H. Honchar, "Species diversity of wild bees (Hymenoptera: apoidea) in parks of kyiv," Bulletin of Taras 
Shevchenko National University of Kyiv. Series: Biology, vol. 78, no. 2, pp. 40-49, 2019.

[89] H. Y. Honchar and A. M. Gnatiuk, "The diversity of wild bees (hymenoptera, apoidea) in MM Gryshko national botanical garden of the NAS of Ukraine," The Kharkov Entomological Society Gazette, vol. 26, no. 2, 2018. 